ISSN: 0514-7336 — ISSN electrónico: 2386-3943

DOI: https://doi.org/10.14201/zephyrus202187209226

\title{
UN NUEVO PAVIMENTO ROMANO DE LA BAETICA: EL LLAMADO 'MOSAICO DE LOS DELFINES' DE NAEVA (CANTILLANA, SEVILLA)
}

\section{A new Roman Pavement from Baetica: the so-called 'Dolphin Mosaic' from Naeva (Cantillana, Seville)}

\author{
Sebastián Vargas-Vázquez*, Guadalupe López Monteagudo** y José Antonio Valiente de Santis*** \\ * Dpto. de Prehistoria y Arqueología. Facultad de Geografía e Historia. Univ. de Sevilla. Cl María de Padilla, s/n. \\ 41004 Sevilla. Correo-e: svargas2@us.es. ID ORCID: https:/lorcid.org/0000-0002-6015-412X \\ ** Núnez de Balboa, 40, 1. ${ }^{\text {C. }} 28001$ Madrid. Correo-e: guadalupelopez@ih.csic.es. ID ORCID: https://orcid. \\ org/0000-0003-0106-5108 \\ *** Arqueólogo. C/ Virgen de Luján, n. ${ }^{\circ} 42,8 .^{\circ}$ B. 41011 Sevilla. Correo-e: arqueologosevilla@gmail.com. ID \\ ORCID: https://orcid.org/0000-0002-1045-9101
}

Recepción: 31/12/2020; Revisión: 3/03/2020; Aceptación: 28/03/2021

Resumen: Se analiza un mosaico recientemente descubierto en la antigua ciudad de Naeva, cuya cronología podría inscribirse en el s. III d. C. por sus características estilísticas y por los datos derivados del estudio de materiales que evidencian el abandono del edificio en el que se enmarca este pavimento musivo a finales de dicha centuria. El trabajo profundiza, además, en la principal particularidad del mosaico, que estriba en su aspecto formal, al cubrir toda la superficie del impluvium y del brocal de un pozo, de un atrium columnado posiblemente perteneciente a una importante domus urbana. La temática representada en el mosaico, dotado de rica policromía, compagina los elementos de agua y tierra mediante la representación, localizada en el suelo, de una abundante fauna íctica y de una singular escena de sátiros y ménades enmarcados en un ambiente de espesas vides, desarrollada en torno al brocal del pozo. A todo ello habría que sumar el carácter efectista del conjunto, provocado por el agua y la posible inundación del centro del atrio, preparado para contener en momentos determinados una lámina de agua que concedería mayor realismo a la escena marina.

Palabras clave: Hispania romana; domus urbana; recubrimiento musivo, impluvium; fauna íctica; sátiros y ménades; vides.

АвSTRACT: We analyse a mosaic recently discovered in the ancient city of Naeva, whose chronology could be dated to the $3^{\text {rd }}$ century $\mathrm{AD}$ due to its stylistic peculiarities and the data derived from the study of materials that show the abandonment of the building in which this mosaic pavement is framed at the end of that century. The work also explores the main peculiarity of the mosaic, which lies in its formal aspect, as it covers the entire surface of the impluvium and the rim of a well, of a colonnaded atrium possibly belonging to an important urban domus. The theme represented in the mosaic, which is richly polychrome, combines the elements of water and earth through the representation, located on the floor, of abundant fish fauna and a unique scene of satyrs and maenads framed in an environment of thick vines, developed around the well's rim. To all this we should add 
the dramatic nature of the whole, caused by the water and the possible flooding of the centre of the atrium, prepared to contain a sheet of water at certain times, which would make this marine scene more realistic.

Key words: Roman Hispania; Urban domus; Mosaic Covering; impluvium, Ichthyofauna; Satyrs and Maenads; Vines.

\section{Introducción ${ }^{1}$}

El proyecto puesto en marcha por los técnicos del Área de Cohesión Territorial de la Diput. de Sevilla y del Ayto. de Cantillana, para la reurbanización de la zona comprendida entre las calles Cristo de la Misericordia, Iglesia y Sacristán José Díaz Hidalgo de Cantillana-Pfoea-2017, comprendió, entre otras actuaciones, la sustitución de la pavimentación, de la red de saneamientos y del alcantarillado de estas calles. Por su parte, la Delegación Territorial de Cultura de Sevilla, de la Junta de Andalucía, consideró que dicha actuación debía estar supervisada y controlada por un técnico arqueólogo, teniendo en cuenta el gran potencial arqueológico de la zona afectada, donde podría estar ubicado el centro neurálgico de la antigua ciudad romana de Naeva (Figs. 1 y 2). La importancia de esta actividad arqueológica radica en ser la primera intervención urbana que se realiza en Cantillana.

La Actividad Arqueológica Preventiva de control de movimientos de tierras, dirigida por J. A. Valiente de Santis, comenzó el 16 de noviembre de 2017, produciéndose, en el transcurso de los trabajos, el descubrimiento de un brocal de pozo completamente recubierto de mosaico, lo que provocó la ampliación del área afectada que, en un principio, se limitó a una zanja excavada en tramos de unos $6 \mathrm{~m}$ de longitud, de 0,50 $\mathrm{m}$ de anchura y 1,40 de profundidad.

1 Trabajo financiado por el vi Plan Propio de Investigación y Transferencia de la Univ. de Sevilla (VI PPIT-Us). Este trabajo se inscribe en el marco del Proyecto $\mathrm{I}+\mathrm{D}+\mathrm{i}$ "Vivere in urbe. Arquitectura residencial y espacio urbano en Corduba, Ategua e Ituci. Investigación y socialización" (PID2019-105376GB-C43), concedido por el Ministerio de Ciencia e Innovación de España, cuyos IIPP son Á. Ventura Villanueva y S. Vargas Vázquez. Agradecemos la identificación de las especies ícticas a los Dres. A. Morales y E. Roselló, profesores de la Univ. Autónoma de Madrid.
La ampliación programada sacó a la luz un espléndido atrium pavimentado con el mosaico que centra el interés de este estudio, cuya cronología, como veremos más adelante, podría enmarcarse en el s. III d. C. Al producirse este hallazgo en plena calle, los límites de la excavación se ciñeron exclusivamente al perímetro del impluvium aunque, en algunos puntos, se documentó el arranque de las galerías que lo circundaban, sin que estas hayan podido ser excavadas en extensión.

\section{El mosaico}

Las dificultades en las que se ha visto envuelto el descubrimiento de este magnífico mosaico, entre las que destacan las limitaciones del espacio a excavar, no permite todavía abordar en profundidad detalles en torno al complejo edilicio al que perteneció. Especialmente porque, por el momento, no se han podido excavar otras estancias que ayuden a definirlo con mayor precisión.

Lo más probable es que el mosaico formara parte de la decoración de una de las ricas domus de la ciudad romana de Naeva. En concreto, estaría pavimentando el impluvium de un atrium cuyo pórtico se sustenta sobre ocho columnas con fustes de ladrillo de 0,45 m de diámetro. Dichas columnas muestran un acabado en estuco en tono crema y un grado de preservación desigual, conservando algunas de ellas hasta $1 \mathrm{~m}$ de alzado, mientras que otras han desaparecido por completo. Lo poquísimo que se ha podido excavar del pórtico pone de manifiesto que también se encontraría pavimentado con mosaico. De este último solo se puede ver su arranque, decorado con diábolos que definen formas curvas que se decoran con crucetas, y que está realizado con teselas blancas y negras de $1 \mathrm{~cm}^{2}$ de lado.

Las propias características del atrium y la presencia de un sumidero de mármol, en forma de 
flor hexapétala, indican que se trataba de un patio abierto en el que las aguas de lluvia se recogían en

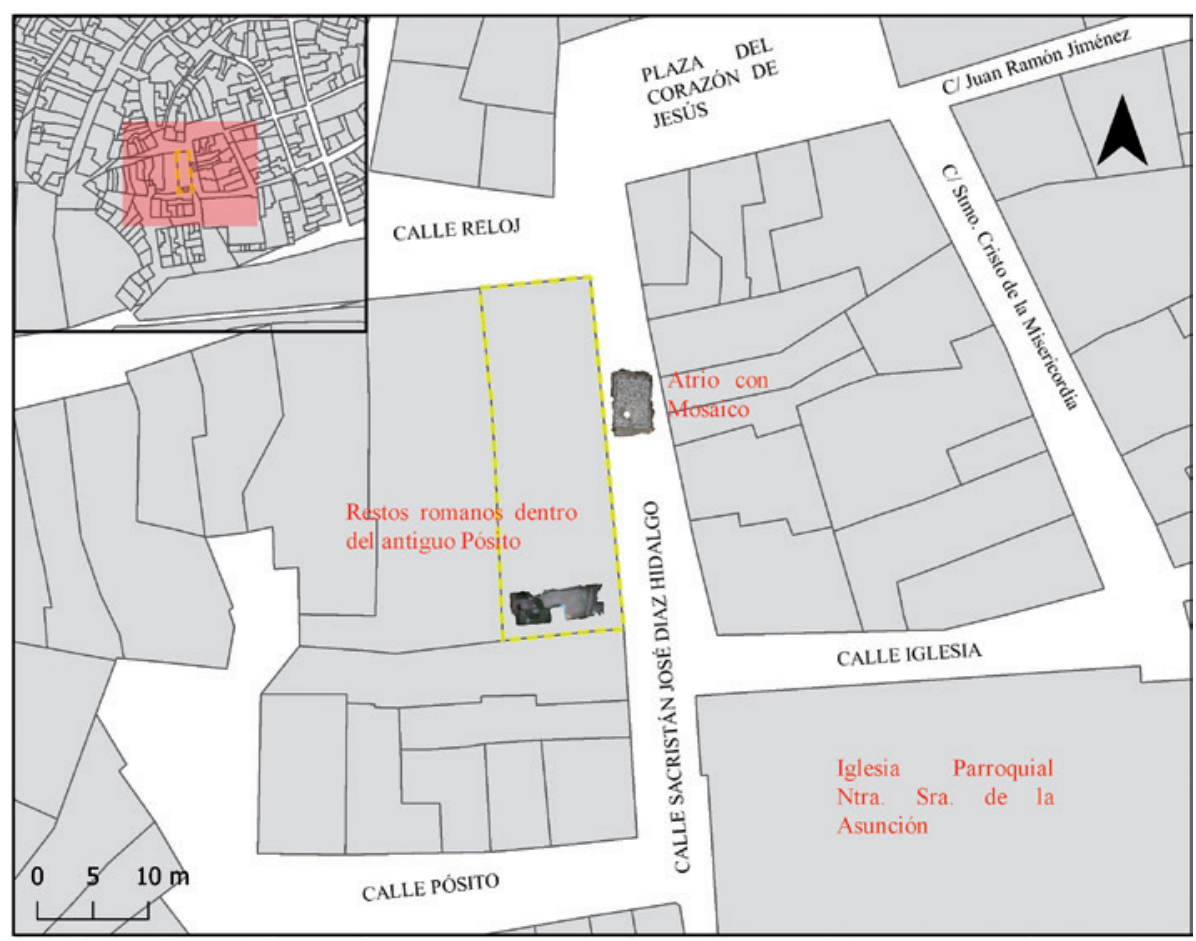

FIG. 1. Localización espacial en el callejero de Cantillana del atrium pavimentado con el mosaico examinado.

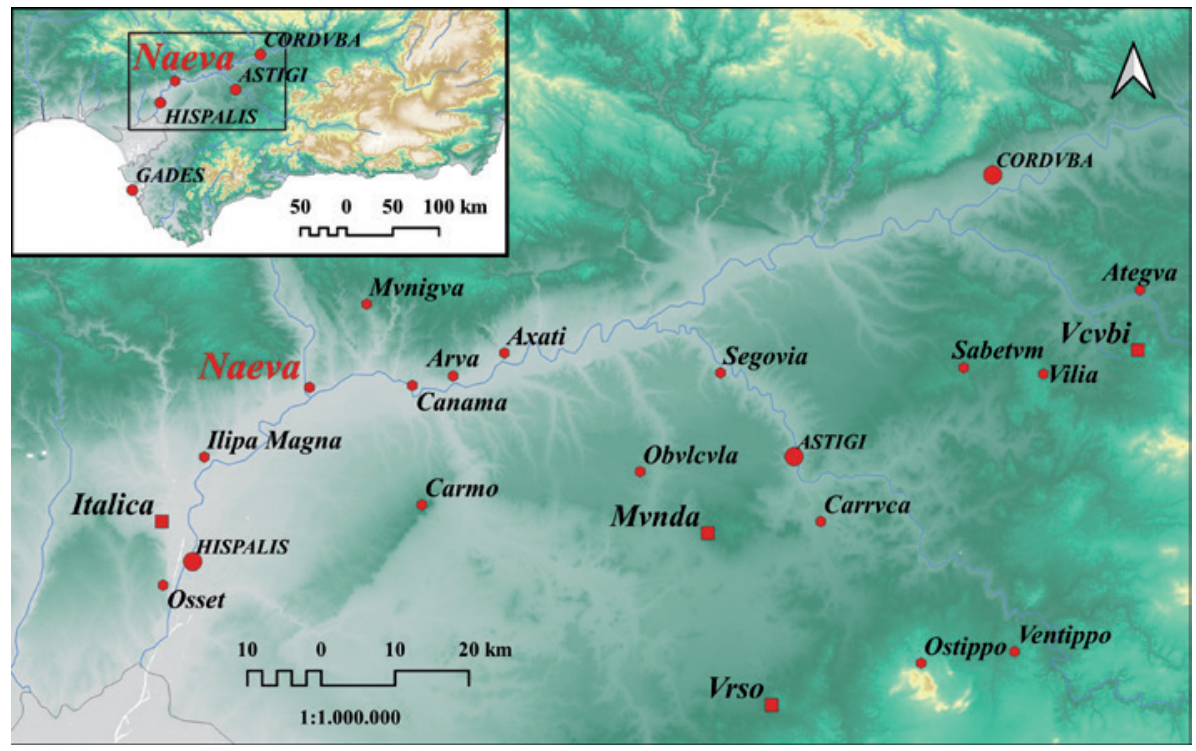

FIG. 2. Localización de Naeva y de otras ciudades romanas del entorno más próximo en la zona meridional de Hispania (imagen elaborada por A. López Núñez y S. Vargas-Vázquez). una cisterna subterránea. Además, el atrium cuenta con la presencia de un pozo que, al no estar conectado con la cisterna, pone de manifiesto que estaba destinado a cumplimentar las necesidades de agua de la domus. La actividad arqueológica permitió explorar dicho pozo hasta los $8 \mathrm{~m}$ de profundidad, a partir de la cual debió suspenderse la auscultación al encontrarse colmatado por escombros. El análisis estratigráfico parece indicar que el pozo ya existía en el momento de construcción del mosaico.

El impluvium tiene una superficie de 14,43 $\mathrm{m}^{2}$ y se encuentra pavimentado en su totalidad con un rico mosaico de tema marino (Fig. 3), cuya escena principal, enmarcada por una trenza polícroma de dos cabos, delimitada por sendos filetes negros, está compuesta por un total de 82 figuras de fauna íctica de distintas especies, todo ello haciendo uso de una rica policromía sobre un fondo manifiestamente blanco. El tamaño de las teselas también es de aproximadamente $1 \mathrm{~cm}^{2}$.

En la configuración final del mosaico, las distintas especies marinas parece que se mueven en un sentido u otro sin seguir un orden aparente; 


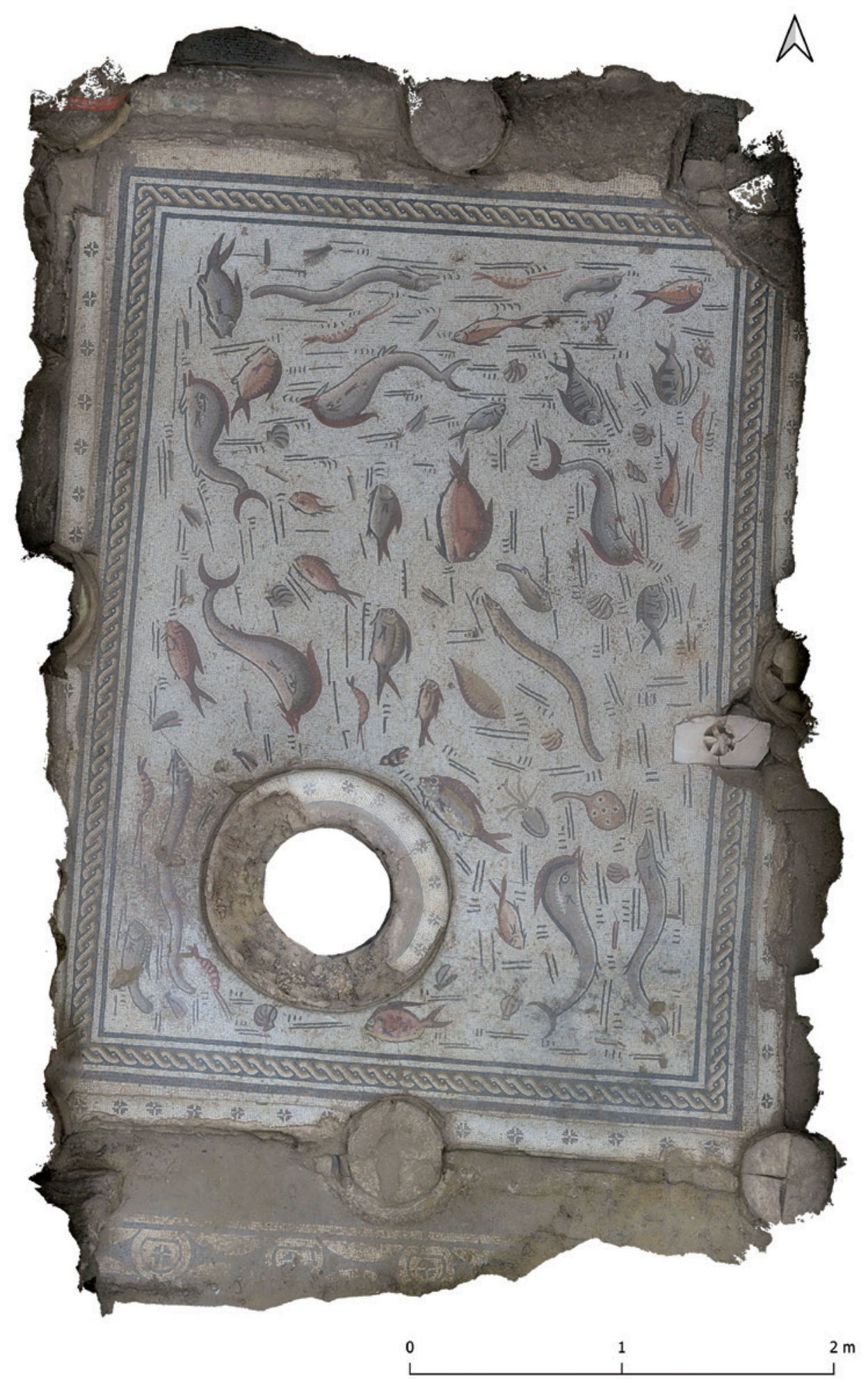

Fig. 3. Plano cenital del mosaico hallado en Naeva (cortesía de A. M. Pérez, M. J. León y J. C. Mejías). 
sin embargo, es muy probable que el artesano aplicara ese modo de representarlas de manera consciente, con objeto de crear la sensación de movimiento y de conseguir múltiples puntos de vista, de forma que el mosaico pudiera ser observado desde cualquier punto de las galerías del pórtico. La maestría de los artesanos que desarrollaron el mosaico permite, además, que la variada fauna marina, delfines, moluscos, crustáceos y peces, sea fácilmente identificable, pese a que en ocasiones se introduzcan rasgos muy estilizados. Se pueden contar cinco delfines,

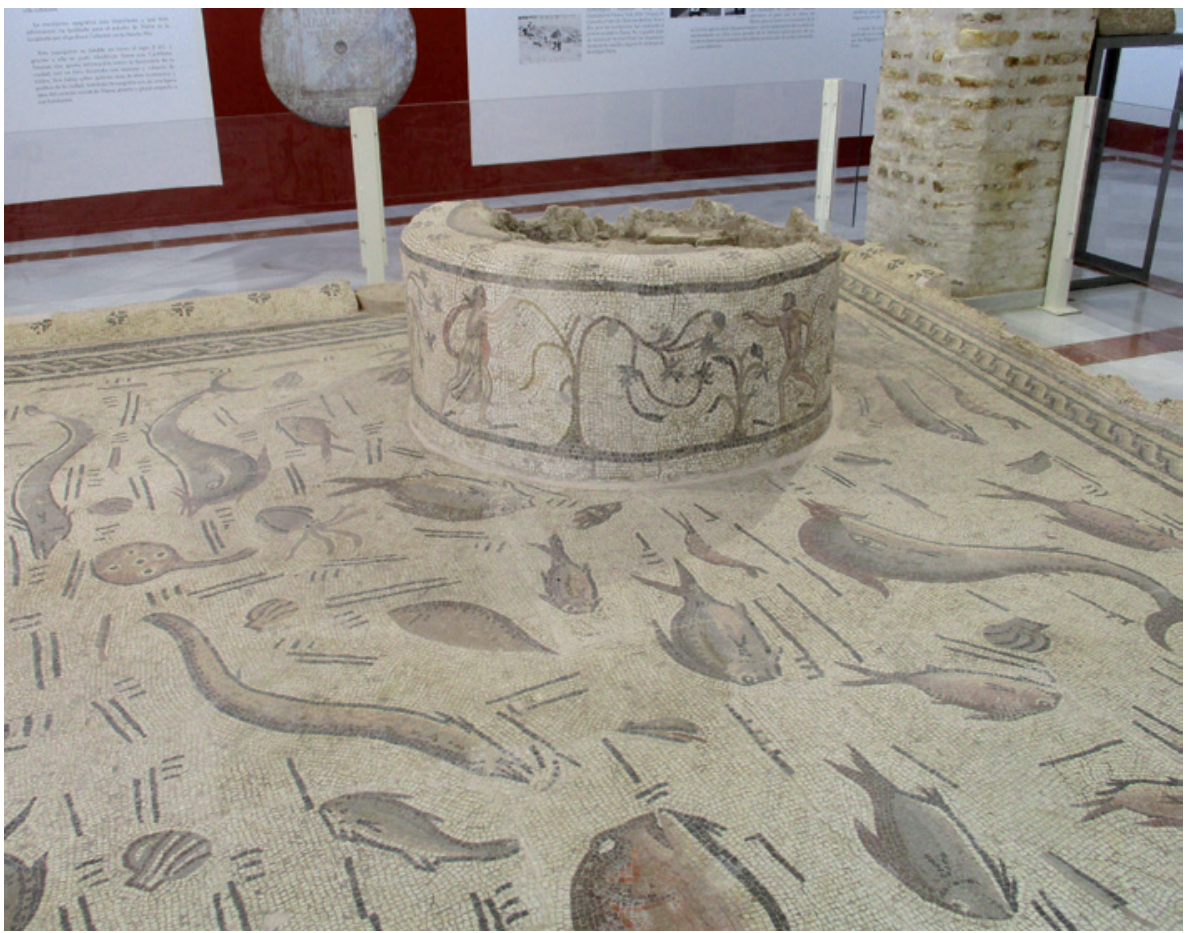

FIG. 4. Vista parcial del pavimento musivo y del que cubre el brocal del pozo (S. VargasVázquez). cuatro morenas, calama-

res, sepias, gambas, navajas, caracolas, vieiras, ostras o mejillones y gran número de peces de distintas especies entre los que destacan dos cuyo cuerpo alargado carece de aleta caudal; en azul aparece un pez plano que, en virtud de esa cola, podría ser algún tipo de lenguadina -Synaptura-; luego está el Torpedo marmorata -la tembladera, con sus ocelos en el dorso- en amarillo, y, por último, en función del barreado de los flancos un sargo -Diplodus sargus-; algunos incorporan caracteres de salmonetes -Mullus-, palometas -carángidos de distintos géneros y con las caudales muy largas y delgadas y el pedúnculo caudal muy estrecho- y de espáridos -brecas, pargos y afines- en proporción variable. Hay un par de peces con una aleta dorsal falciforme oscura y muy desarrollada, tal vez interpretación libre del autor o representación de un pez exótico -es decir, no mediterráneo-, de los que existen algunos casos en el mar Rojo y océano Índico, aunque con cuerpos bastante diferentes. No obstante, es difícil especular sobre los distintos tipos de peces ya que están demasiado estilizados y más bien son representaciones de modelos 'estándar' idealizados.

Una particularidad de este taller es, sin duda alguna, esa forma acentuada de representar la aleta caudal de algunos peces, en forma de cresta, como también ocurre con los delfines, aunque en este caso concreto se siguen cánones muy asentados y establecidos en el mundo romano a la hora de representarlos. La profundidad y el efecto de movimiento se acentúan claramente con los continuos movimientos de agua, conseguidos con la representación de trazos negros de distintos tamaños y direcciones, que se distribuyen de manera abundante por todo el mosaico. Se trata de una forma esquemática generalizada de representar el agua en el resto de los mosaicos hispanos en blanco y negro y policromos de época imperial, mediante líneas dentadas; trazos rectos, ondulados o quebrados; en zigzag; en forma de C, S, E y F; 'peines', todos ellos recursos utilizados para producir sensación de movimiento en el agua, y también triángulos formados por trazos paralelos 


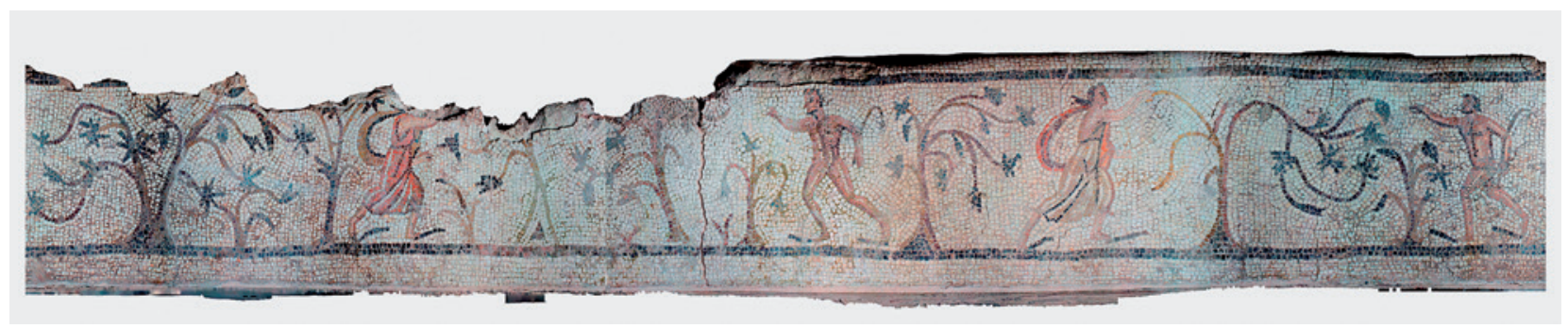

Fig. 5. Vista panorámica del brocal (S. Vargas-Vázquez y A. López Núñez).

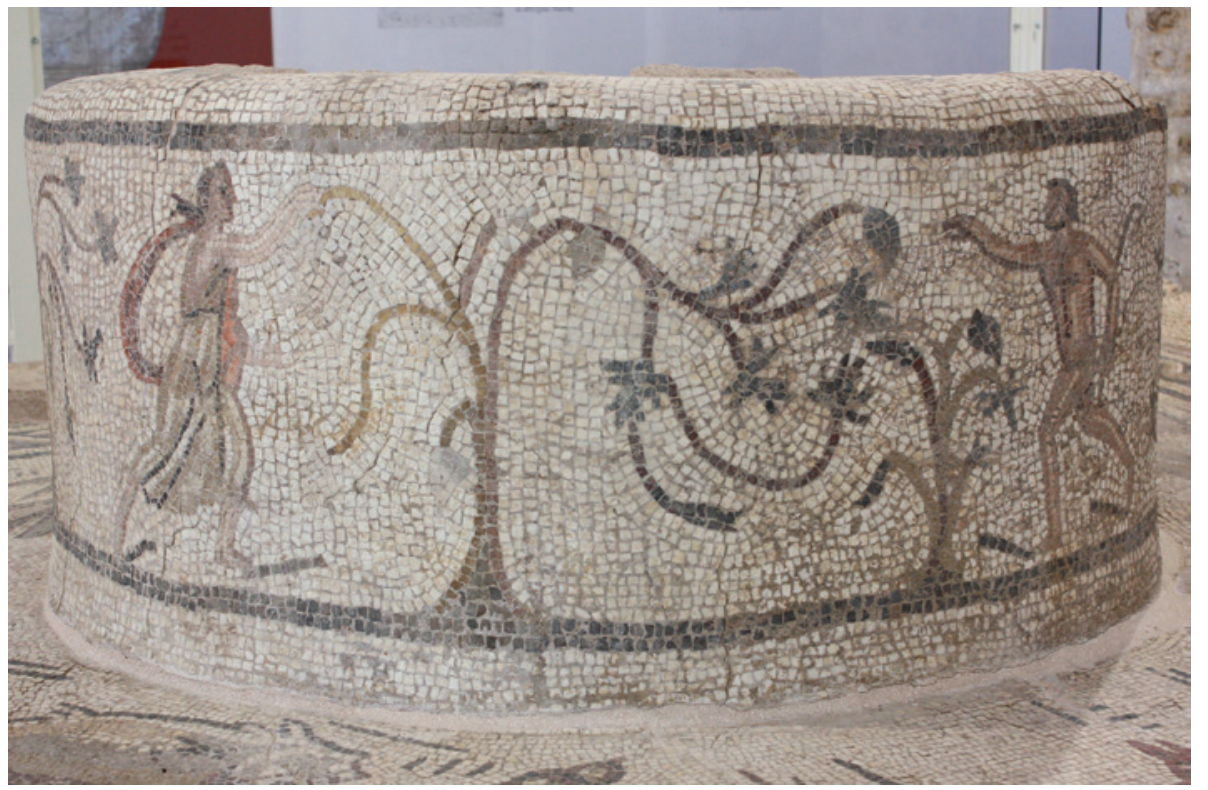

FIG. 6. Detalle del brocal en el que se aprecia la variedad de uvas negras y blancas (S. VargasVázquez).

coronados por una $\mathrm{v}$, que se han dado en llamar 'moscas de agua', y remolinos denominados 'flores de agua', figuras que deja el agua al tropezar con un pequeño obstáculo en sus movimientos de flujo y reflujo. Aun así, el efecto general que transmite el pavimento es de calma y relajación, todo lo cual invita a la contemplación meditada del conjunto.

El mar, la fauna marina y las distintas especies ícticas que lo pueblan aparecen frecuentemente representados en los mosaicos hispano-romanos, como tema principal de la composición ocupando toda la superficie del pavimento, o como motivo secundario de orlas y compartimentos acompañando a un tema principal (Acuña, 1973; 1974; 2001-2002: 365-374; 2013: 143-157; Hauschild, 1994: 285-291; González Fernández, 2005: passim; López Monteagudo, 2008: 2547-2568; Mourão, 2008: passim; Mourão, 2011: 344-351)2. Algunos mosaicos hispanos constituyen verdaderos catálogos de fauna marina, en los que a veces las distintas especies se han representado solamente una vez o, a lo sumo, dos; baste recordar el espléndido mosaico de los peces de Tarragona (Balil y Mondelo, 1985: 251256). Salvo unos pocos ejemplares tempranos realizados en blanco y negro, y otros de fechas más tardías, entre los que cabe destacar, por su cercanía, los mosaicos de las termas romanas de la Cuesta del Rosario de Sevilla, de cronología ya de hacia mediados del s. II d. C. ${ }^{3}$, la práctica totalidad de los mosaicos hispanos con representación de especies marinas, de época alto- y bajoimperial, están realizados en rica policromía, siguiendo la tradición helenística de los mosaicos de Pompeya y, como en estos y en los del resto del Imperio, entre los que destacan los de Túnez y Argelia (Dunbabin, 1978:

2 López Monteagudo, G.: Mosaicos hispano-romanos de aguas. Sevilla: Univ. de Sevilla, en prensa.

3 Vera (1987: 55 y 59-60), aunque Collantes (1977: 70-72) data este complejo termal en fechas más tardías. Además cf. Beltrán et al., 2005: 77-78; González Fernández, 2011: 61-72. 


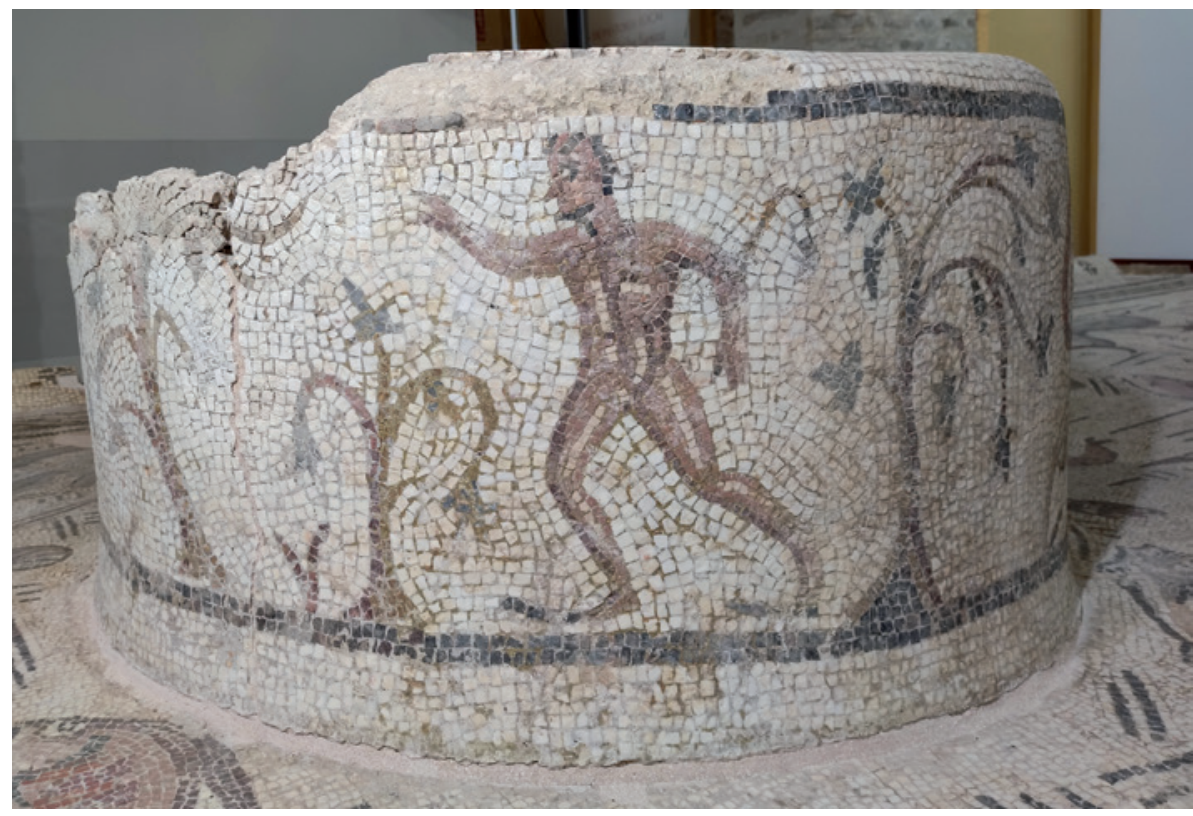

Fig. 7. Detalle del brocal con sátiro (S. Vargas-Vázquez).

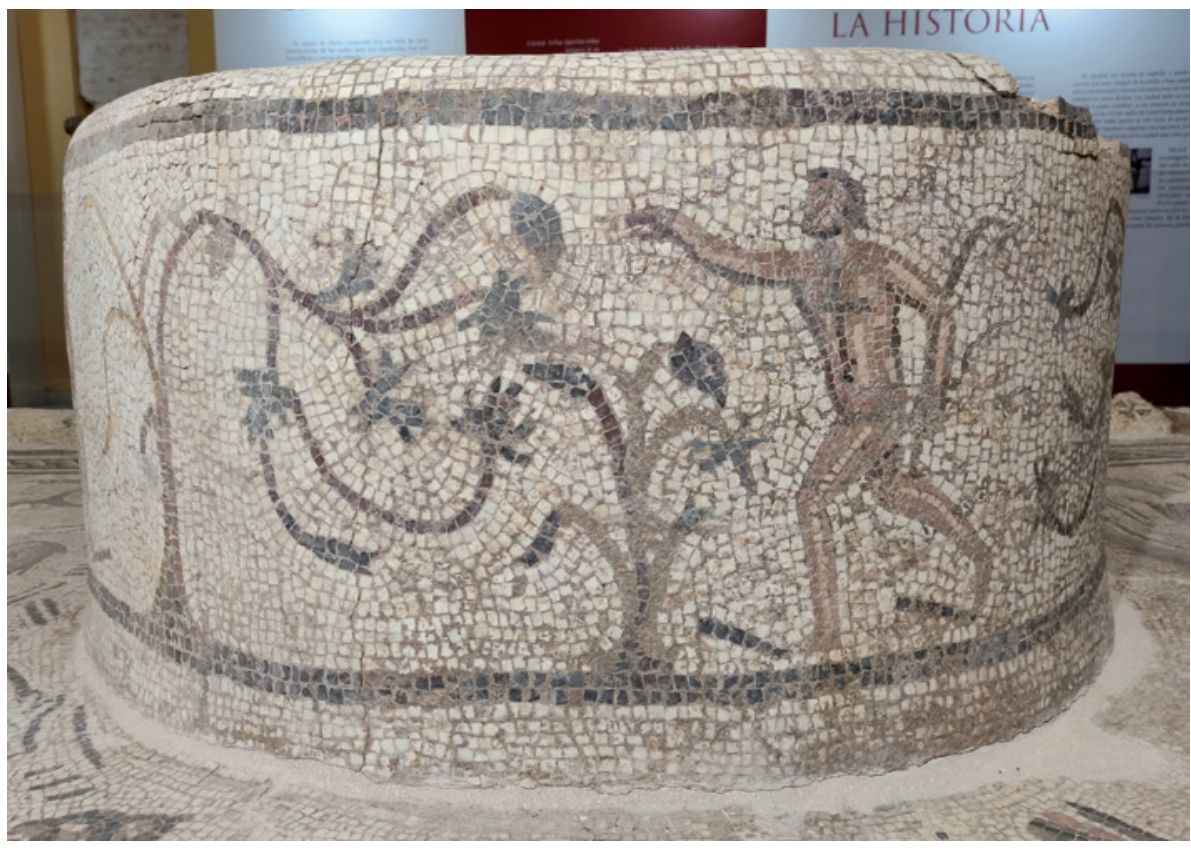

FIG. 8. Detalle del brocal con sátiro (S. Vargas-Vázquez). color, movimiento naturalista, etc., de forma que en la mayoría de los casos se pueden reconocer con claridad las distintas especies representadas, aunque en otras ocasiones lo que se busca es ofrecer un panorama marino genérico mediante la utilización de estereotipos. Este tipo de pavimentos se colocaba por lo general en espacios de agua, tipo atrios, peristilos, jardines, termas, en fuentes, piscinas y estanques de triclinia, recubriendo no solamente el suelo a veces escalonado, sino también las paredes, con lo que se buscaba un efecto de mayor realismo al convertirse con el movimiento del agua en motivos dinámicos.

Circunscribiéndonos a la Bética, los mosaicos polícromos con decoración de distintas especies ícticas, realizados con mayor o menor habilidad artística, se documentan en numerosos pavimentos sevillanos procedentes de Italica, Astigi, La Lantiscosa (Villanueva del Río), Peñaflor y Osuna, en otros de Córdoba y Fuente Álamo, de Antequera (Málaga) y de Salar (Granada), entre otros ${ }^{4}$.

125-130; Dunbabin, 1999: passim; Ferdi, 1998 : passim), los animales han sido minuciosamente retratados en el agua, con toda clase de detalles en cuanto a sus características individuales, tamaño,

4 También López Monteagudo, op. cit. n. 2. 


\section{El puteal}

Desplazado hacia la esquina sur del atrio se alza el brocal de un pozo o puteal (Fig. 4), de 1,10 $\mathrm{m}$ de diámetro exterior y una altura de $0,50 \mathrm{~m}$, fábrica de ladrillo y completamente revestido de mosaico. Su estado de conservación, salvo una ruptura provocada en su momento por la caída de una de las columnas, es, como también ocurre con el mosaico del suelo, impecable.

El efecto y la visión del conjunto, suelo y puteal, es unitario, por cuanto el manto teselado del primero continúa por toda la superficie del segundo, todo lo cual se ve reforzado gracias al fondo blanco del conjunto, que permite que el mosaico del suelo se alce sobre el brocal y lo cubra por completo.

En lo que a la decoración del puteal se refiere, la temática cambia claramente, mostrando todo el conjunto la dicotomía agua/tierra, ambiente marino en el suelo, como ya hemos visto, $y$ terrestre

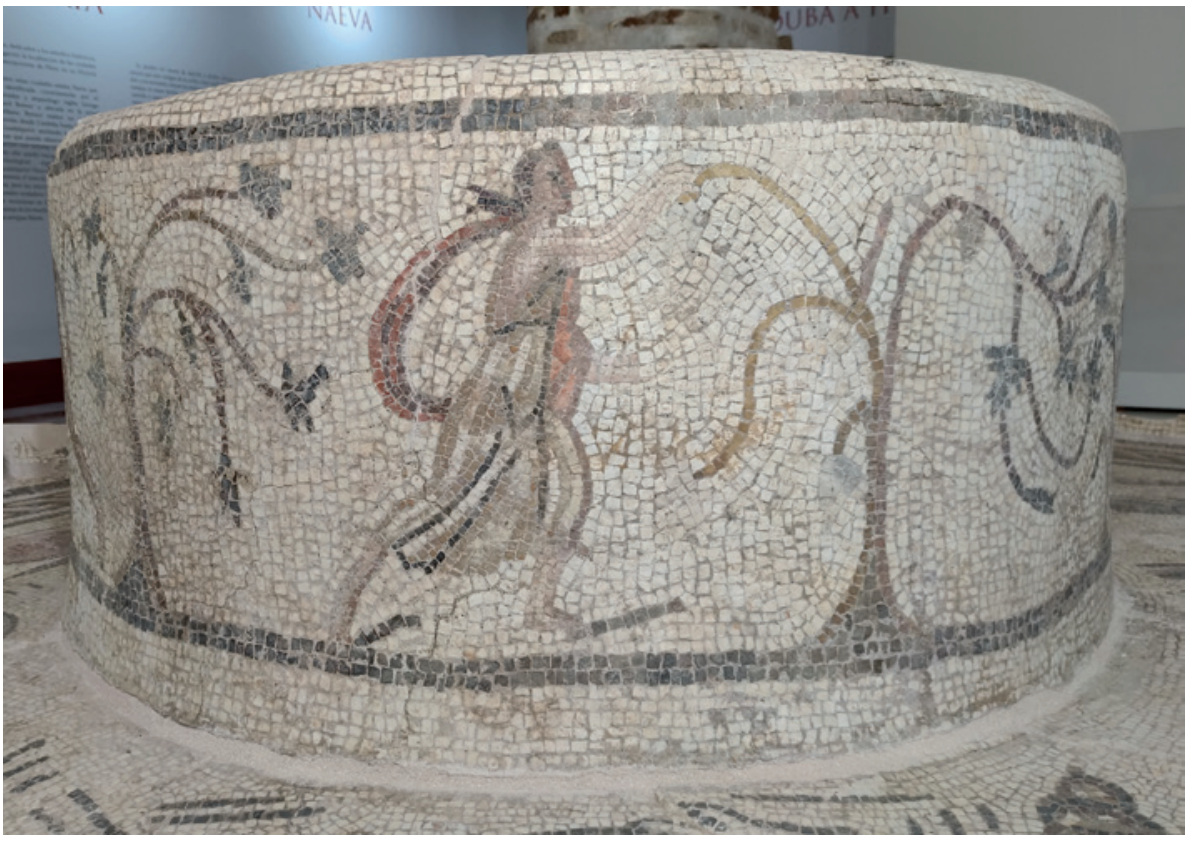

Fig. 9. Detalle del brocal con ménade (S. Vargas-Vázquez).

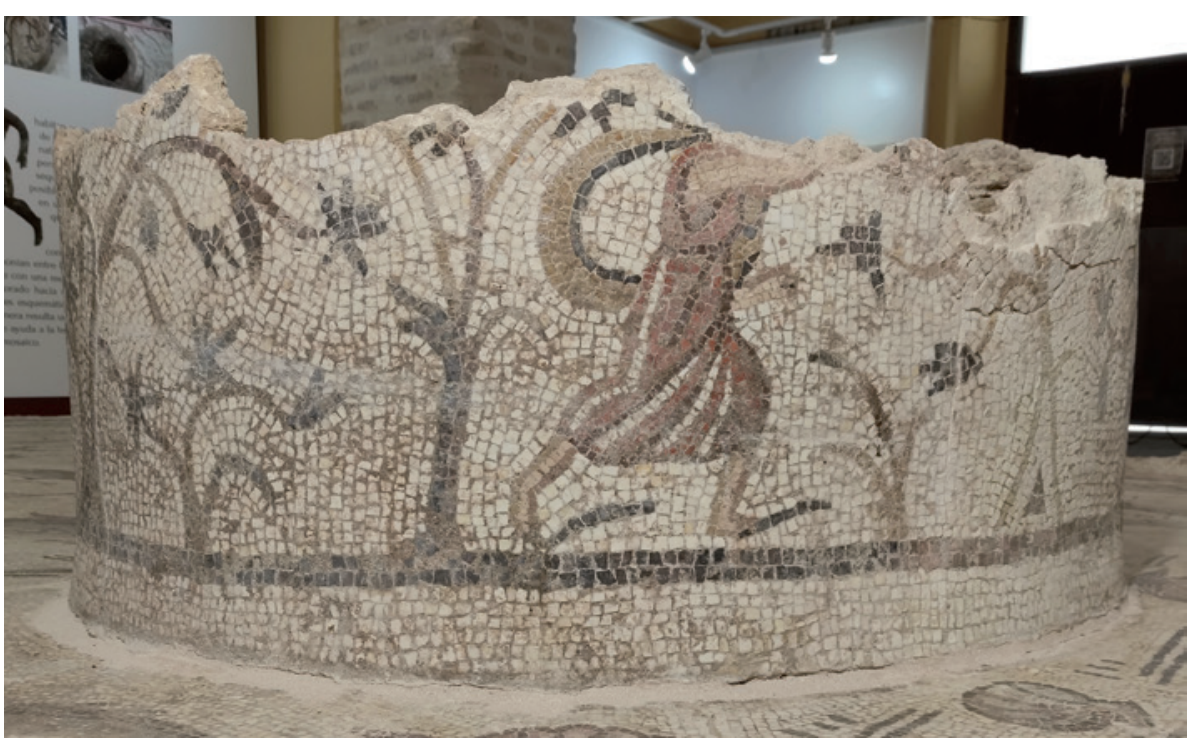

FIG. 10. Detalle del brocal con ménade. Foto S. Vargas Vázquez. en el puteal. Este último

muestra un tema muy extendido y asentado en los mosaicos de la Bética, quizás el que más, como es el báquico (López Monteagudo, 2010: 67-93; Vargas-Vázquez y López Monteagudo, 2016: 419-420, 426). La escena, en su conjunto, se desarrolla sobre una línea negra que aísla, por decirlo de alguna manera, la representación que tiene lugar en tierra del ambiente acuático. El coronamiento del brocal muestra una cenefa delimitada por dos filetes negros y decoración de crucetas o rosetas. 
En un entorno cubierto de vides y parras, dos ménades y dos sátiros se mueven agitados alternativamente por parejas en torno a las plantas, cargadas de racimos, que se expanden por toda la superficie circular del pozo (Fig. 5). Ambas parejas quedan separadas, igualmente, por unas vides que en su conjunto se representan de forma muy simplificada, destacando los frutos, que se dibujan en forma de piña o almendra. Destacan los colores de estos últimos, al alternar las variedades de uvas negras y blancas, especialmente visible en la vid representada en la Figura 6, en la que la rama cercana a la ménade da frutos blancos y la próxima al sátiro negros, un detalle singular por cuanto no solo cambia el color de los frutos, sino también el de las ramas que parten de una misma planta, como si de un claro injerto se tratara, pudiendo estar en consonancia asimismo con el color de la piel de los protagonistas.

Por lo que respecta a las figuras de sátiros y ménades, tres de ellas se conservan al completo y solo a una de las ménades le faltan la cara y parte de un brazo, debido a una ligera ruptura que afecta al brocal. Los sátiros se muestran desnudos y con pedum, mientras que las ménades se cubren por completo con chiton y peplos. Uno de los sátiros, con pelo negro y perilla (Fig. 7), posee una nariz bastante marcada y puntiaguda, y en ningún caso muestran los falos (Fig. 8), algo habitual en este tipo de representaciones. Una de las ménades lleva chiton en tono ocre y manto anaranjado y rojizo, pelo largo y recogido en una cola que se eleva en movimiento (Fig. 9). En la otra ménade los colores de la vestimenta se invierten, el chiton ahora es rojizo y anaranjado y el manto ocre (Fig. 10). La cabeza y parte del brazo es lo único que falta de esta última figura. Las sombras de cada personaje se representan de manera muy esquemática a través de una línea negra.

La actitud de todos ellos es de airoso movimiento, como indica la postura de las piernas y de los brazos, que se potencia en el caso de las ménades por el velo que se infla a sus espaldas. Ménades y sátiros deambulan entre las vides alcanzando los racimos de uvas, como si estuvieran poseídos por el éxtasis de la embriaguez y el sonido de la música

Ediciones Universidad de Salamanca / 요요 del cortejo de Baco, avanzando dos a dos hacia un mismo punto para encontrarse (Fig. 5).

Pese a que el tema de sátiros y ménades danzantes se encuentra muy extendido por todo el mundo romano, localizándose en todo tipo de soportes, la realidad es que estamos en presencia de un unicum, por esa conjunción temática y porque los sátiros y las ménades actúan como protagonistas del thiasos inmersos en un campo de vides y parras, recogiendo y/o recolectando uvas, claramente en el caso de las ménades, y caminando, dos a dos, en actitud de danza pausada para encontrarse en un punto común, sin la algarabía ni el frenesí que en ocasiones suelen acompañar a este tipo de representaciones. Se trata de una iconografía insólita desconocida en la musivaria romana, en la que lo más cercano es la representación de ménade y sátiro, enfrentados y con un racimo de uvas, que figura en uno de los medallones octogonales del mosaico dionisiaco de Colonia (Parlasca, 1959: 75-79; Dunbabin, 1999: 81 y 83). En otros soportes, el tema de sátiros y ménades enfrentados, aunque con claras diferencias por la ausencia de las vides y las uvas, se constata en dos paneles resueltos en opus sectile de Pompeya (Elia, 1929: 265-276); en el Mosaico de Ganimedes de la Domus Sollertiana de El Djem (Ben Abed, 2006: 75), separados ambos personajes por una columna, y en el de las termas de Trajano de Acholla (Ben Abed, 2006: 92).

Como ocurre con otras representaciones iconográficas, es muy probable que el tema del mosaico de Cantillana tenga su origen en el mundo griego, donde se documentan escenas de sátiros y ménades recogiendo uvas, como en la copa del Pintor de Chiusi, presidida por el gorgoneion, de $c .520$ a. C. (LIMC, Dionysos 407 y 447), y mucho más cercano, aún, en la Copa de figuras negras de Nikosthenes (Díez, 2013: 778, fig. 9.37), del s. vi a. C., conservada en el Museo del Louvre (n. ${ }^{\circ}$ inv. N 3494; n. ${ }^{\circ}$ cat. F 124), en la que ménades y silenos, en presencia de Dionisos, deambulan entre parras cargadas de racimos, interponiéndose estas últimas entre los personajes, como también ocurre en nuestro brocal. Sin duda alguna, esta última copa constituye un modelo muy cercano para el mosaico de 
Cantillana, pese a la presencia de Dionisos y al hecho de que en este caso parece que son los silenos los que cogen los frutos.

El tema de la vendimia por parte de erotes y putti sí que se ha documentado en mayor cantidad en otros mosaicos del imperio o de zonas próximas como los de Emerita del Mosaico de Orfeo (Álvarez, 1990: 37-49, láms. 10-12), de Seleucus y Anthus y de Venus (Blanco, 1978: 30-32 y 44, láms. 32 y 73), de Astigi (Vargas-Vázquez et al., 2018: 73-75, fig. 64), de Saguntum, Calpe y Duratón, por poner unos ejemplos (Blázquez,

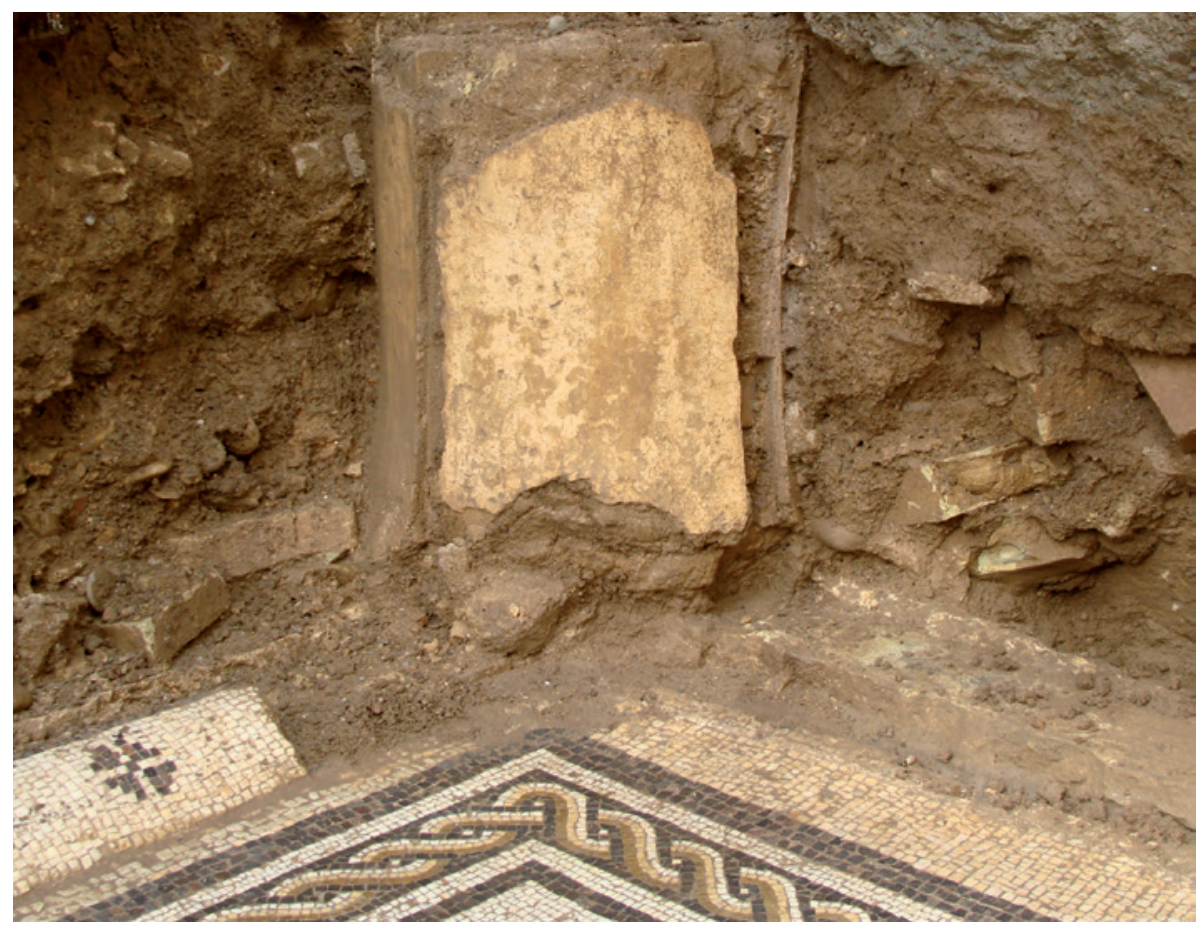

FIG. 11. Detalle de una de las columnas y de la media caña hidráulica (imagen J. A. Valiente de Santis).

1984: 69-96; Mourão, 2016: 202-224). Fuera de Hispania los erotes y putti vendimiadores figuran en numerosas escenas musivas de carácter mitológico, a pie o subidos a la escalera en el mosaico blanco y negro presidido por Baco de la necrópolis de Santa Rosa en Roma; y ya en policromía, entre otros, en el Mosaico de Baco e Ikarios de la Casa de los Laberii en Oudna; en el pavimento del Triunfo Báquico de El Djem, en el que se representan las vides que surgen de cuatro cráteras situadas en los ángulos y los personajes y animales del thiasos báquico; en un mosaico de Dougga; en el pavimento de las Bodas de Thetis y Peleo de Cherchel; en el Mosaico de Licurgo y Ambrosia de Piazza Armerina, donde los erotes vendimian las vides que surgen de las piernas de Ambrosía (Dunbabin, 1978: 173-187; Balmelle y Darmon, 2005: 899-921; López Monteagudo, 2012: 680-682).

Más habitual es que los sátiros, otras veces personajes reales, figuren como pisadores de uva en el lagar, por lo general en número de tres, cogidos de la mano o agarrados a una cuerda situada en la parte alta, para no perder el equilibrio y caerse: mosaicos de Astigi, Italica, Emerita, Complutum y Duratón, y ya fuera de Hispania de Saint Roman-en Gal, en los pavimentos norteafricanos de Cherchel y Lambaesis, y también erotes o putti en el mosaico de Santa Constanza, dentro del contexto cristiano que el motivo pagano por excelencia de la vid y el vino asume con la nueva religión, como símbolo de resurrección y esperanza en la otra vida (Balmelle y Darmon, 2005: 899-921; Vargas-Vázquez et al., 2017: 62-65).

Por otra parte, la presencia de sátiros o silenos y ménades en compañía, danzando o en estado de éxtasis, se ha documentado en múltiples soportes, aras y puteales, cerámica, sarcófagos, etc., sirva de ejemplo el altar cilíndrico del teatro de Italica (García y Bellido, 1951: 117-154; Beltrán, 2009: 299; Jiménez, 2014: 51). También se puede ver en los mosaicos de Colonia (Parlasca, 1959: 75-79; Dunbabin, 1999: 81 y 83), Thuburbo Majus (LIMc, Dionysos/ Bacchus [in per. occ.] 88; Pan 87), Hellín (Blázquez 
et al., 1989: 49-54; Simón, 2020: 122-124; Sogorb, 1987: 21-40), y formando parte del cortejo de Baco en los pavimentos hispanos de Complutum (Fernández Galiano, 1984: 148-168) y Noheda (Valero, 2013: 307-330; 2015: 439-443) y en los mosaicos sobre todo del n de África procedentes de El Djem, Sousse, Djemila, Saint Leu (Dunbabin, 1978).

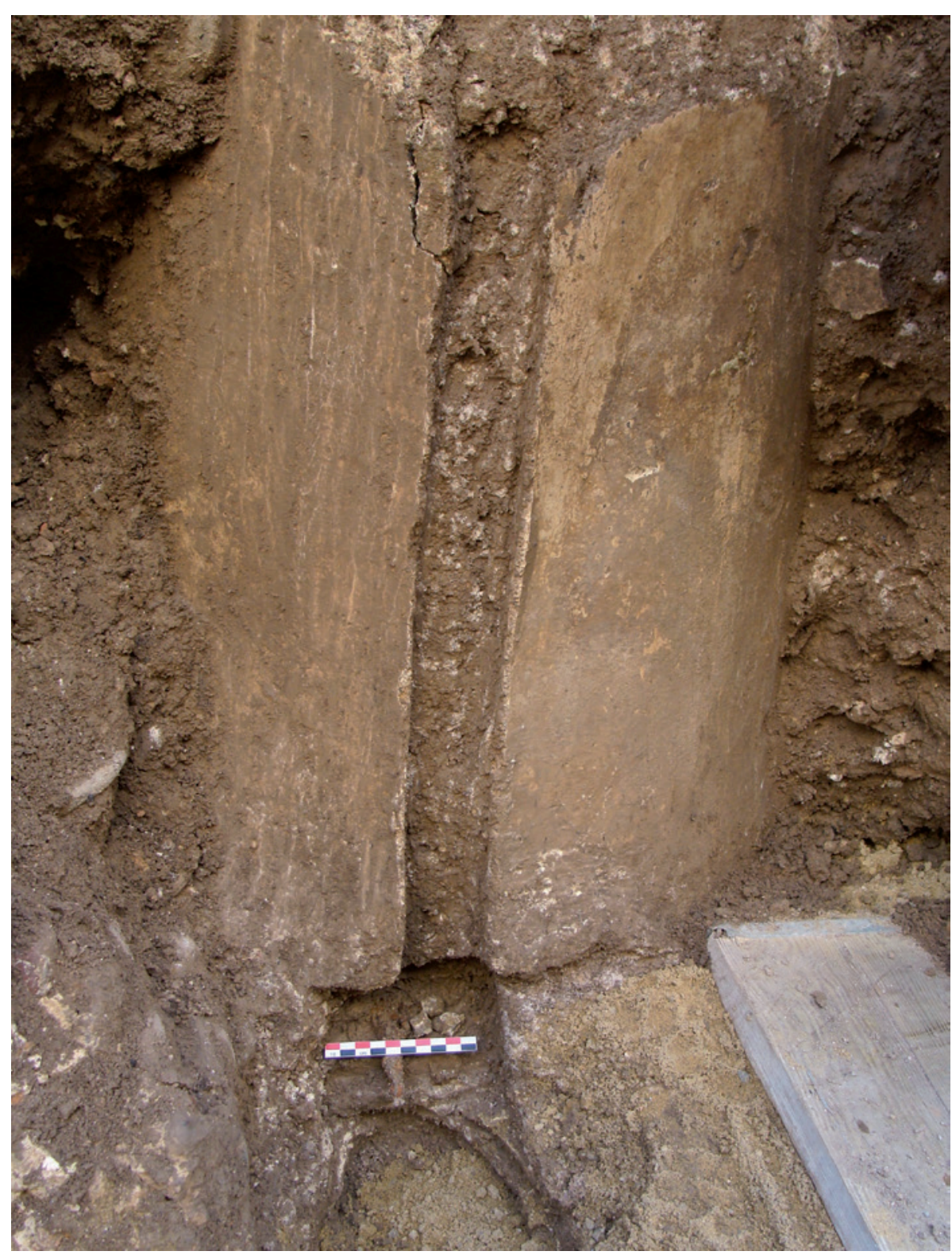

FIG. 12. Detalle de una de las columnas donde se observa el encaje de la pieza que cerraba el impluvium (J. A. Valiente de Santis).
Las imágenes báquicas de Cantillana, en su conjunto, no tienen paralelos en otros mosaicos de la Bética ni del Imperio. Junto a las particularidades de la representación, con sátiros y ménades enfrentados que parecen buscarse, envueltos en un frondoso campo de vides y parras, destaca la forma de representar a las ménades o bacantes con velo inflado por el movimiento. Aspecto este último poco habitual, aunque en la Bética se documenta en los mosaicos báquicos de la colección Cruz Conde de Córdoba (Blázquez, 1981: 29-30, fig. 13, láms. 13-16; López Monteagudo, 2018: 91-92), de Alcolea de Córdoba (Blázquez, 1981: 4043, láms. 25-30, 85-88; López Monteagudo, 1998: 179-210; López Monteagudo, 2018: 93) y de Fuente Álamo (López Monteagudo et al., 1988: 786-795; López Monteagudo, 2018: 96-97; Vargas-Vázquez, 2016: figs. 17 y 19), y ya en Lusitania en la zona absidada del Mosaico de los Aurigas de Mérida (Blanco, 1978: 45-46, lám. 77), siempre formando parte del thiasos. Sin embargo, la presencia de las vides y parras lo aproxima, pese a sus notorias diferencias, a los mosaicos astigitanos del Tigerreiter (Vargas-Vázquez et al., 2017: 62-65, fig. 47) y de los Amores (Vargas-Vázquez et al., 2017: 81-83, fig. 70a; García-Dils y 
Ordóñez, 2019: 39-47), en los que las parras forman parte de la narración báquica.

\section{El impluvium y su conexión con la galería porticada}

El mosaico se completa con una media caña hidráulica recubierta con un fondo blanco teselado decorado con crucetas negras en la cara que mira hacia el mosaico y, al parecer, lisa en aquella otra que mira a las galerías del pórtico. Se trata de un recurso utilizado en otros lugares, como en el gran estanque ovoidal de Piazza Armerina, en donde la presencia de una ligera canaleta conservada a lo largo del perímetro de tres lados del pórtico y la inclinación del suelo del pavimento hacia el punto de salida del colector principal confirman el contexto de agua provisto de canalizaciones para el funcionamiento de al menos seis fuentes de agua que también alimentan el ninfeo (Gallocchio y Pensabene, 2010: 333-340). Lo mismo ocurre con los encuentros del suelo y las paredes de las galerías del peristilo de la villa de la Estación, y en su singular galería en rampa, y aunque en este caso la caña hidráulica no se encuentra teselada, sí que vuelve a poner de manifiesto el contexto de agua que debió reinar en momentos determinados, junto con la parte central del peristilo, en todos estos espacios. En Lusitania encontramos este mismo recurso en el frigidarium del balneum de Mérida puesto al descubierto en 2009 en el solar del antiguo cuartel Hernán Cortés, pavimentado con un mosaico blanco y negro datado en el s. III d. C. El mosaico presenta varias

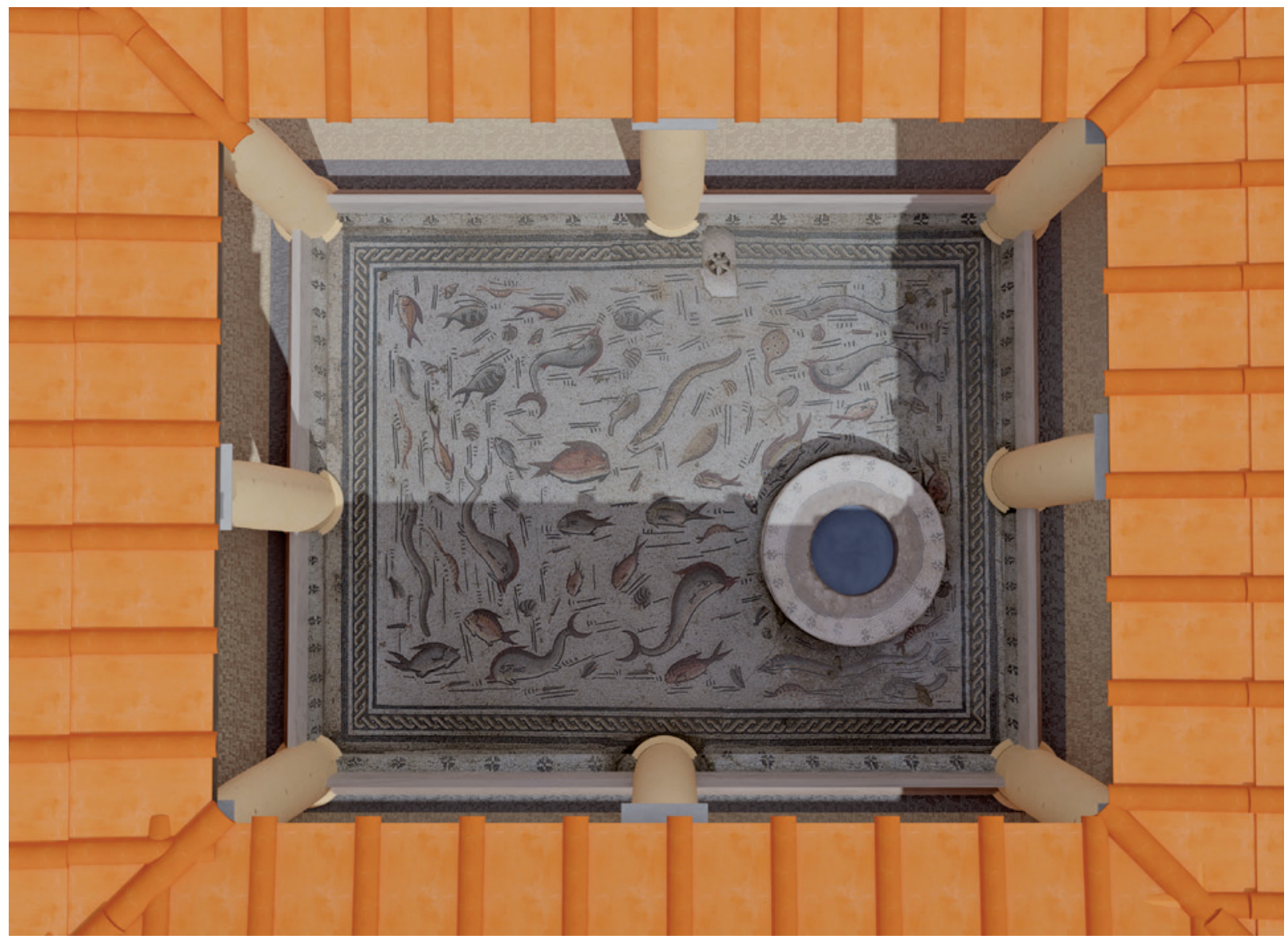

Fig. 13. Hipótesis de reconstrucción del atrium (S. Vargas-Vázquez y A. Villarejo de Torres). 


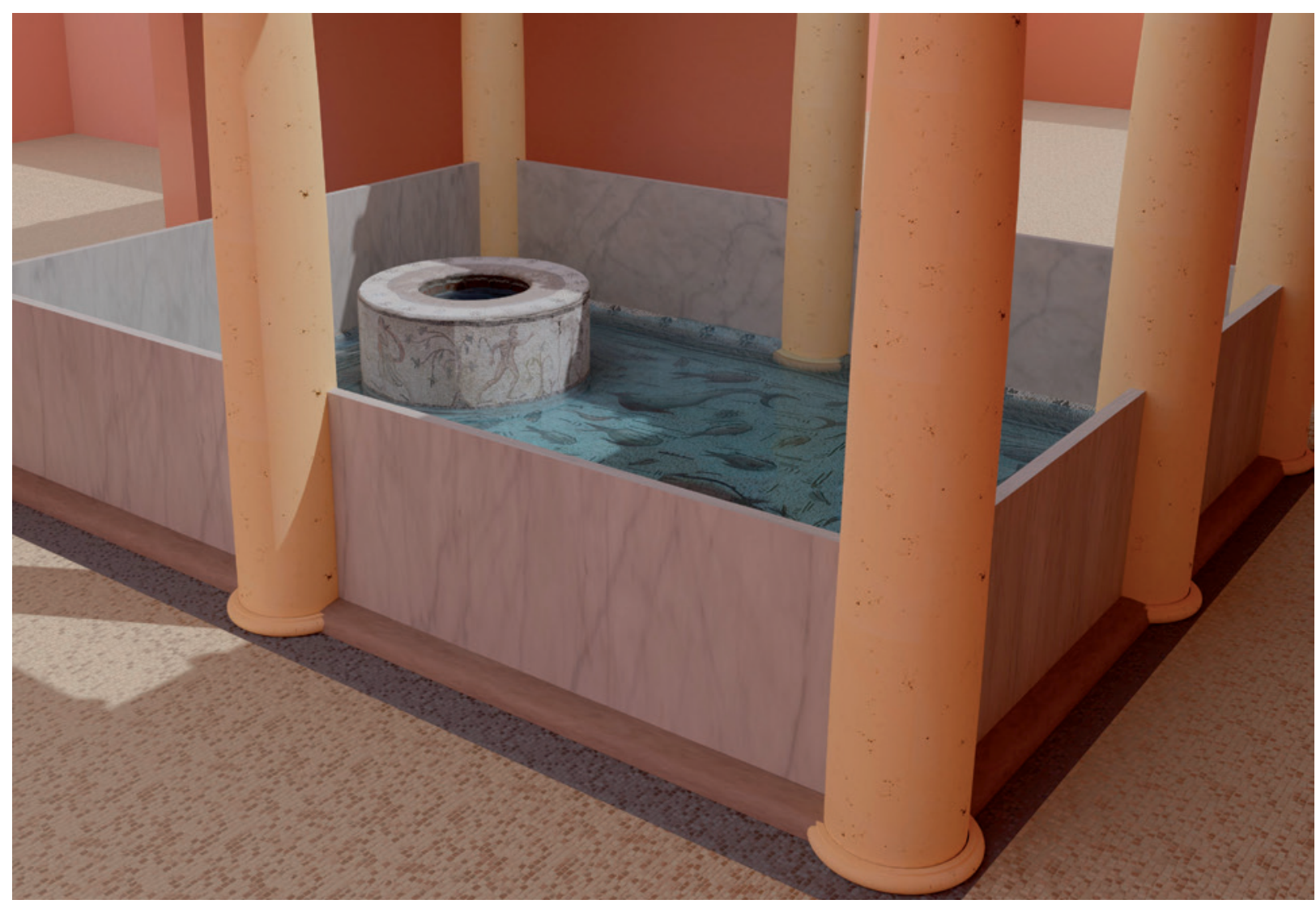

Fig. 14. Hipótesis de reconstrucción del atrium con el impluvium ligeramente inundado (S. Vargas-Vázquez y A. Villarejo de Torres).

especies de fauna íctica, realizadas con una técnica muy plana, sin ningún volumen ni indicación de profundidad en el fondo, aunque sí de movimiento con resultados poco artísticos, dispuesto sobre un suelo anterior rematado en media caña, con la que se adosa a un banco corrido5.

5 Agradecemos la información a los responsables de la excavación de dicho complejo termal, F. Sánchez Hidalgo y D. Sanabria. Sánchez Hidalgo, F. (2010): Memoria de la Excavación arqueológica en el Antiguo Cuartel de Hernán Cortés: Mérida. Memoria de excavación inédita depositada en el Consorcio de la ciudad monumental de Mérida. También el artículo en prensa de Sánchez Hidalgo, F. y Sanabria, D.: "Dos espacios termales extramuros en la Augusta Emerita romana y tardoantigua (solar del antiguo Cuartel 'Hernán Cortés'. Mérida”. En Monografías Arqueológicas de Mérida.
El análisis estratigráfico de todo el conjunto pone de manifiesto que el mosaico se configuró completamente plano hasta los límites de la galería porticada, sobre este monta la media caña hidráulica que forma el límite entre ambos espacios, centro del atrio y galería. La media caña se encuentra interrumpida en el centro por un surco de $6 \mathrm{~cm}$, que evidencia el encaje de algún elemento que cerraba el atrio, completamente desaparecido y que bien pudiera ser un zócalo de mármol o de otro material que no fuera madera, por los problemas que generaría su contacto con el agua y la humedad. Dicha marca del anclaje del cerramiento del peristilo se percibe también en las columnas (Figs. 11 y 12), poniendo en este caso de manifiesto que el zócalo tendría como mínimo una altura de un metro, en función de lo conservado. Obviamente, todo ello 
puede tener un significado funcional, evitar que la humedad y el agua de lluvia pudieran acceder a los pórticos, o simplemente delimitar los espacios, pero también pudo poseer un marcado carácter efectista. En este caso, el taponamiento del sumidero permitiría a los propietarios de la domus verter, en ciertos momentos, una lámina de agua sobre el pavimento con objeto de dar mayor realismo al fondo acuático, de forma que produjera la impresión de ser una piscina llena de fauna marina en constante movimiento (Figs. 13 y 14).

En cualquier caso, el sistema de diferenciar y delimitar los distintos espacios de jardines, peristilos y atrios, parte central y pórticos, por medio del uso de distintos recursos, tales como celosías, muretes y pequeñas tabicas de obra o de placas de mármol, como parece ser el caso que nos ocupa, era muy común y nada singular, siendo muchos los ejemplos documentados, incluso en representaciones pictóricas y escultóricas.

Este tipo de atrios y peristilos claramente vinculados con el agua son, en el mundo romano, más comunes de lo que podamos pensar, y no nos referimos a que puedan contener un surtidor o alguna fuente dentro de ellos, sino a la particularidad de que la mayor parte o toda la superficie que define el espacio central se conciba como una piscina o un estanque, a veces vinculados a ciertos juegos $y$ movimientos de aguas, preparados para que en momentos determinados el dominus pudiera disfrutar de ellos o mostrar a sus visitantes, en un alarde de esplendor y buen gusto. Ejemplos cercanos los tenemos en algunas domus de Itálica, entre las que destaca la Casa de la Exedra. La villa de la Estación, en la localidad malagueña de Antequera, es, quizás, uno de los ejemplos más claros y representativos, con todo el espacio central del gran peristilo convertido en una gran piscina en la que se insertan cuatro grandes islas probablemente decoradas con elementos vegetales, esculturas y surtidores (Romero et al., 2006: 239-258; Romero y Vargas-Vázquez, 2016: 437-447).

El hecho de que todo el impluvium quede cubierto por un mosaico es, igualmente, un aspecto bien conocido en el mundo romano, siendo comunes, también, los impluvia recubiertos con opera sectilia. Los paralelos en mosaicos serían muchos, pero por poner solo algún ejemplo de mosaico cubriendo un impluvium de dimensiones reducidas traemos a colación aquel de la domus documentada en la calle de Lladó de Badalona (Balil, 1964: 91-93), conocida como la Casa de los Delfines. Ya en espacios más amplios, como en nuestro caso, lo encontramos en la cercana villa del Alcaparral, en Casariche, Sevilla, donde el impluvium aparece decorado con un bello mosaico con representación de nereidas acompañadas de peces (De la Hoz y Jiménez, 1987: 373-375; Hidalgo y Vargas-Vázquez, 2016: 684-688; Vargas-Vázquez y López Monteagudo, 2016: 428); y en la villa de Caserío Silverio, en Antequera, Málaga, en la que de nuevo el centro del peristilo se encuentra pavimentado con un mosaico que también contiene algunas representaciones de peces. En este caso, la superficie teselada cubre y se extiende sin solución de continuidad por todo el peristilo, decorando el espacio central y los pórticos, con temas distintos aunque probablemente relacionados entre sí (Vargas-Vázquez y Romero, 2014: 152-159).

Por lo que respecta a la cronología, el estudio de materiales del estrato que sella el abandono de la domus cuyo atrio pavimenta nuestro mosaico pone de relieve la presencia de cerámicas pertenecientes al ajuar doméstico, como ollas, tapaderas, jarras, platos, cazuelas y cuencos de terra sigillata sudgálica e hispánica, de lucernas y de ánforas, cuya cronología marcan una fecha tope a finales del s. III d. C. Este hecho nos permite ratificar que para esas fechas el edificio ya se encuentra en desuso y abandonado, marcando una fecha ante quem para el mosaico analizado. Este dato, junto con algunos indicios que muestra el propio mosaico, sin entrar en detalles en el análisis de paralelos por las complicaciones que ello entraña, basadas en las formas más o menos esquemáticas de las representaciones, sobre todo de las escenas báquicas que se contextualizan en la Bética a finales del s. II y en adelante, permiten encuadrar claramente este mosaico en el s. III d. C. 


\section{Conclusión}

Los nuevos hallazgos arqueológicos descubiertos en el solar de la antigua ciudad romana de Naeva, bajo los cimientos de la actual Cantillana, en la provincia de Sevilla, vienen a sumarse a hallazgos anteriores, restos de decoración arquitectónica, una inscripción y una escultura (Collantes, 1955: 134-137, láms. xxxi, cx y cxi; Beltrán, 1988: 163-193; Beltrán y Loza, 1993: 62-82), que ponen de manifiesto la importancia de esta antigua ciudad emplazada a los pies del Baetis; si bien, los ahora acaecidos suponen una gran novedad en lo que a la documentación de espacios domésticos se refiere, nunca antes documentados pese a la importancia aludida de la ciudad. Nos estamos refiriendo a la presencia de un atrio pavimentado con un bello mosaico policromo de especies marinas que incorpora el brocal de un pozo recubierto asimismo de mosaico, pero esta vez de temática báquica. La novedad más destacable de este espacio arquitectónico rodeado de ocho columnas de ladrillo estucadas es la existencia de una cańa o bocel a lo largo del impluvium y de un sumidero de mármol en forma de flor de seis pétalos, recurso utilizado para evacuar el agua en otros lugares de Hispania y de la Península Itálica, que ponen de manifiesto que en ocasiones pudo funcionar como estanque o piscina, proporcionando la presencia del agua mayor realismo al fondo marino.

Junto a todo ello, llama la atención la conjunción de temas tan distintos en un mismo pavimento, como son la fauna acuática y las escenas báquicas, cuando lo normal es que la decoración acuática continuara en el puteal o pozo, precisamente por ser el recubrimiento de este una prolongación del mosaico del suelo, aun cuando la decoración de los impluvia con temas acuáticos sea un hecho generalizado y de que la temática báquica se utilice normalmente en la decoración escultórica de los puteales y de las aras, baste recordar por su proximidad geográfica el altar cilíndrico del teatro de Itálica (García y Bellido, 1951: 117-154; Beltrán, 2009: 299; Jiménez, 2014: 51). La conjunción de los temas de agua y los báquicos no es nueva en la Bética, documentándose en un entorno próximo en

Ediciones Universidad de Salamanca / @®ఠ el mosaico astigitano del doble rapto de Europa y de Ganimedes, procedente de una domus del s. III d. C., en el que se ha introducido una herma báquica en el espacio acuático poblado por delfines y otras especies ícticas, dentro del cual el toro de Zeus cabalga briosamente llevando a la princesa sidonia sobre su lomo (Vargas-Vázquez et al., 2017: 110113, fig. 111A).

Desde el punto de vista de las representaciones del mosaico en su conjunto, ícticas y báquicas, podemos asegurar, como ya hemos visto, que denotan una gran singularidad en el conjunto de la Bética y de la Hispania romana, mostrando el conjunto báquico del puteal elementos únicos nunca antes documentados en la musivaria romana, como es la danza iniciática de los sátiros y las ménades en torno a las vides y parras, haciendo alusión al éxtasis alcanzado por los personajes del thiasos báquico tras la ingesta desmesurada del vino, y todo ello resaltado con el juego del contraste de colores. El hecho de que las ménades y los sátiros se muevan entre las parras y vides a la manera de vendimiadores, junto con la representación de frutos blancos y negros, realza la importancia y el valor de la producción vitivinícola reinante en la zona o a la que tal vez se dedicaba el dueño de la domus o imperaba en la zona, mientras que la decoración del fondo marino no tiene ninguna connotación económica, sino meramente decorativa, como es usual en lugares ad hoc, piscinas, estaques, fuentes, termas, etc. Todo lo cual podría girar en torno al exhibicionismo imperante en el seno de la familia propietaria. Ambas representaciones se insertan en un ideal de vida en el que la realidad y la mitología comparten el mismo espacio como expresión de esa anhelada fusión vital.

Por otra parte, la abundante representación de peces que nos ofrece el mosaico del impluvium y los elementos báquicos del puteal, con esa clara diferenciación entre tierra y mar, y los detalles estilísticos y formales, son elementos claros que invitan a pensar en la existencia de grandes talleres, cualificados y bien formados, también en Naeva, a imagen y semejanza de lo que ocurre en zonas cercanas, como Itálica, Écija o Carmona, entre otras ciudades. Las parras de Cantillana con sus racimos 
de uvas parecen haber salido de las mismas manos o de los cartones de modelos existentes en un taller ubicado en Astigi, lo que no es de extrañar teniendo en cuenta la cercanía de ambas localidades, si bien la calidad artística de los talleres de Astigi no es comparable a la de Naeva. Sí lo es el mosaico del suelo con la representación de las distintas especies ícticas, realizadas con gran realismo y perfección técnica y artística, mayor aún que en los mosaicos astigitanos de Oceanos (Vargas-Vázquez et al., 2017: 75-76, figs. 65A-B), de fauna acuática (Vargas-Vázquez et al., 2017: 85, fig. 74) y de roseta de triángulos curvilíneos (Vargas-Vázquez et al., 2017: 69-72, figs. 58-60). Y precisamente esto es lo que más llama la atención en el ejemplar de Cantillana, la diferencia artística existente entre la fauna íctica del suelo, realizada con gran nivel artístico, y las figuras báquicas faltas de técnica y de arte, en la línea del mosaico báquico de Fuente Álamo, y que evidencia las distintas manos que intervinieron en la realización de este pavimento no obstante su continuidad por suelo y pared.

Al mismo tiempo, todos esos elementos artísticos, decorativos y formales que nos muestran el mosaico y el conjunto completo del atrio, con esa particularidad de la separación entre los pórticos y la parte central, que a modo de piscina nos ofrece una rica visión de un fondo marino en pleno y armónico movimiento, pensado además para ser visto desde cualquier punto del pórtico, son el reflejo de esa sociedad opulenta reinante en tantas partes de la Bética, que no duda en ofrecer, a través de sus domus y villae y de la decoración en ellas expresada, indicios de su poder y riqueza, y en ocasiones de su buen gusto y nivel cultural.

\section{Bibliografía}

Acuña, F. (1973): Mosaicos romanos de Hispania Citerior. II. Conventus Lucensis. Santiago de Compostela-Valladolid: Univ. de Santiago de Compostela-Univ. de Valladolid.

Acuña, F. (1974): Mosaicos romanos de Hispania Citerior. III. Conventus Bracarensis. Santiago de
Compostela-Valladolid: Univ. de Santiago de Compostela-Univ. de Valladolid.

Acuña, F. (2001-2002): "Nuevas aportaciones a los mosaicos romanos de Galicia", Anales de Prehistoria y Arqueología de Murcia, 17-18, pp. 365-374.

AcuñA, F. (2013): "De novo sobre o Mosaico de Panxón e outras novas sobre a Musivaria na Gallaecia", Revista da Faculdade de Letras Porto, 12, pp. 143-157.

Álvarez Martínez, J. M. (1990): Mosaicos romanos de Mérida. Nuevos hallazgos. Mérida: Ministerio de Educación, Cultura y Deporte.

BAlil, A. (1964): "Mosaicos romanos de Baetulo (Badalona)", Zephyrus, xv, pp. 85-100.

Balil, A. y Mondelo, R. (1985): "Mosaico con representaciones de peces hallado en las proximidades de Tarragona", Boletín del Seminario de Arte y Arqueología de la Univ. de Valladolid, 51, pp. 251-256.

Balmelle, C. y Darmon, J.-P. (2005): "La vigne et le vin dans la mosaïque romaine et byzantine". En $L a$ Mosaïque Gréco-Romaine Ix, 2. Roma: École Française de Rome, pp. 899-921.

Beltrán, J. (1988): "Frisos de roleos acantiformes en los monumentos epigráficos de la Bética”, Baetica, 11, pp. 163-193.

Beltrán, J. (2009): "El relieve". En León, P. (coord.): Arte romano de la Bética II. Sevilla: Fund. Focus-Abengoa, pp. 277-320.

Beltrán, J.; González Acuña, D. y Ordóñez, S. (2005): “Acerca del urbanismo de 'Hispalis'. Estado de la cuestión y perspectivas”, Mainake, 27, pp. 7778.

Beltrán, J. y Loza, M. L. (1993): “Materiales arqueológicos de época romana procedentes de Naeva (Cantillana, Sevilla)", Cantillana. Cuadernos de Historia Local, 1, pp. 62-82.

Ben Abed, A. (2006): Tunisian Mosaic. Treasures from Roman Africa. Los Angeles: Getty Publications.

Blanco, A. (1978): Mosaicos romanos de Mérida. Corpus de Mosaicos Romanos de España I. Madrid: CsIC.

Blázquez, J. M. (1981): Mosaicos romanos de Córdoba, Jaén y Málaga. Corpus de Mosaicos Romanos de España III. Madrid: CSIC.

Blázquez, J. M. (1984): "Mosaicos báquicos en la Península Ibérica”, Archivo Español de Arqueología, 57, pp. 69-96.

Blázquez, J. M.; López Monteagudo, G.; Neira, M. L. y SAN Nicolás, M. P. (1989): Mosaicos romanos de Lérida y Albacete, Corpus de Mosaicos Romanos de España, VIII. Madrid: csic. 
Blázquez, J. M.; San Nicolás, M. P. y López MonTEAGUDO, G. (2004): "Representaciones mitológicas, leyendas de héroes y retratos de escritores en los mosaicos de época imperial en Siria, Fenicia, Palestina, Arabia, Chipre, Grecia y Asia Menor", Antigüedad y Cristianismo, xxI, pp. 341-342.

Collantes, F. (1955): "Cantillana (Sevilla). Huerta Alta”, Noticiario Arqueológico Hispánico, II (1-3), pp. 134-137, láms. Xxxi, Cx y CXI.

Collantes, F. (1977): Contribución al estudio de la topografia sevillana en la Antigüedad y en la Edad Media. Sevilla: Real Academia de Bellas Artes de Santa Isabel de Hungría.

De la Hoz, A. y JimÉnez, J. (1987): "Informe de la segunda campaña de excavaciones en la villa romana de "El Alcaparral' (Casariche, Sevilla)". En Anuario Arqueológico de Andalucía 1986. Sevilla, t. III, pp. 371-379.

Díez, F. (2013): "Dioniso en la figuración arcaica". En Bernabé, A.; Jiménez, A. I. y Santamaría, M. A. (coords.): Dioniso. Los origenes (Textos e imágenes de Dioniso y lo dionisiaco en la Grecia antigua). Madrid: Liceus, pp. 275-399 y 763-801.

Dunbabin, K. M. D. (1978): The Mosaics of Roman North Africa. Oxford: oup.

Dunbabin, K. M. D. (1999): Mosaics of the Greek and Roman World. Cambridge: cup.

Elia, O. (1929): "Di due panelli decorativi pompeiani con figure in 'opus sectile' ad intarsio", Bollettino d'Arte, vi, anno IX, pp. 265-276.

Ferdi, S. (1998): Mosaïques des eaux en Algérie. Un langage mythologique des pierres. Algérie: Régie Sud Méditerranée.

Fernández Galiano, D. (1984): Complutum, II. Los mosaicos. Madrid: Ministerio de Cultura.

Gallocchio, E. y Pensabene, P. (2010): "Rivestimenti musivi e marmorei dello Xystus di Piazza Armerina alla luce dei nuovi scavi”. En Angeleldi, C. y SalveTTI, C. (coords.): Atti del XV Colloquio dell'Associazione Italiana per lo Studio e la Conservazione del Mosaico (AISCOM). Tivoli: AISCOM, pp. 333-340.

García y Bellido, A. (1951): "El puteal báquico del Museo del Prado", Archivo Español de Arqueología, 24, n. 83-84, pp. 117-154.

García-Dils, S. y Ordóñez, S. (2019): El mosaico de los Amores de Zeus de la Plaza de Armas de Écija. Un nuevo pavimento musivo de Colonia Augusta Firma. Écija (Sevilla): Real Academia de Ciencias, Bellas Artes y Buenas Letras 'L. Vélez de Guevara' de Écija.

GonZÁlez Acuña, D. (2011): Forma urbis Hispalensis. El urbanismo de la ciudad romana de Hispalis a través de los testimonios arqueológicos. Sevilla: Univ. de Sevilla, Fund. Focus-Abengoa.

González Fernández, E. (2005): Domus Oceani. Aproximación a la arquitectura doméstica de Lucus Augusti. Lugo: Concello de Lugo.

Hauschild, T. (1994): "Die Mosaiken am Podium des Wasserheiligtums com Milreu, Estoi (Portugal)”. En Darmon, J. P. y Rebourg, A. (eds.): La Mosä̈que Gréco-Romaine IV. Paris: Association Internationale pour l'Étude de la mosaïque antique, pp. 285-291.

Hidalgo, R. y Vargas-VÁzquez, S. (2016): "El Alcaparral”. En Hidalgo, R. (coord.): Las villas romanas de la Bética I, Catálogo. Sevilla: Univ. de Sevilla, pp. 684-692.

Jiménez, A. (2014): “Basa neoática”. En López, J. R. y Beltrán, J. (eds.): Itálica, Cien años, Cien piezas. Sevilla: Junta de Andalucía-Diput. Sevilla, p. 51.

López Monteagudo, G. (1998): "Sobre una particular iconografía del triunfo de Baco en dos mosaicos romanos de la Bética", Anales de Arqueología Cordobesa, 9, pp. 179-210.

López Monteagudo, G. (2008): "Las riquezas de las aguas en los mosaicos hispano-romanos", L'Africa Romana, xviI, pp. 2547-2568.

López Monteagudo, G. (2010): "Mosaicos romanos de la Bética”. En León, P. (coord.): Arte romano de la Bética, III. Sevilla: Fund. Focus-Abengoa, pp. 67-93.

López Monteagudo, G. (2012): "Paisajes productivos del agro en los mosaicos romanos del Norte de África", L'Africa romana, xix, pp. 669-690.

López Monteagudo, G. (2018): "Reflexiones sobre los mosaicos cordobeses”, Antiquitas, 30, pp. 83-108.

López Monteagudo, G.; Blázquez, J. M.; Neira, L. y San Nicolás, M. P. (1988): "El simbolismo del matrimonio en el mosaico de Fuente Álamo (Puente Genil, Córdoba) y otros mosaicos hispanos inéditos", Latomus, 47 (4), pp. 786-795.

Mañas, I. (2011): Mosaicos romanos de Itálica (II). Corpus de Mosaicos Romanos de España XIII. Madrid-Sevilla: CsIC-Univ. Pablo de Olavide.

Mourão, C. (2008): Mirabilia Aquarum. Motivos aquáticos em mosaicos da Antiguidade no território portugués. Lisboa: Empresa Portuguesa da Águas Livres, SA.

Mourão, C. (2011): "Mosaicos romanos com motivos aquáticos em Portugal". En $O$ mosaico romano nos centros e nas periférias. Originalidades, influências e ide. Conímbriga: Instituto dos Museus e da Conserva, pp. 344-351. 
Mouráo, C. (2016): “A vendimia nos mosaicos hispano-romanos como expressâo de um ecumenismo paradisíaco”. En Maciel, J. y Mourão, C. (coords.): Imagens do Paradeisos nos Mosaicos da Hispania. Classical and Byzantine Monographs, 85. Amsterdam: Adolf M. Hakkert Publisher, pp. 202-224.

Parlasca, K. (1959): Die römische mosaiken in Deutschland. Berlin: De Gruyter.

Romero, M.; Mañas, I. y Vargas-Vázquez, S. (2006): "Primeros resultados de las excavaciones realizadas en la Villa de la Estación (Antequera, Málaga)", Archivo Español de Arqueología, 79, pp. 239-258.

Romero, M. y Vargas-Vázquez, S. (2016): "La Estación (Antequera, Málaga)". En Hidalgo, R. (ed.): Las villas romanas de la Bética, 2. Sevilla: Univ. de Sevilla, pp. 437-447.

Simón, N. (2020): "Mosaicos de época romana con temática de las estaciones en el actual territorio de Castilla-La Mancha”, Arqueología y Territorio, 17, pp. 121-128.

Sogorb, M. C. (1987): "Los mosaicos de la villa romana de Hellín”, Boletín del MAN, v (1-2), pp. 21-52.

VAlero, M. A. (2013): "The late-antique villa at Noheda (Villar de Domingo García) near Cuenca and its mosaics", Journal of Roman Archaeology, 26, pp. 307-330.
Valero, M. A. (2015): "Los mosaicos de la villa de Noheda (Villar de Domingo García, Cuenca)". En Trovabene, G. (ed.): Atti XII Colloquio AIEMA (Venezia, 2012). Verona: Scripta edizioni, pp. 439-443.

VArgas-VÁzquez, S. (2016): "Pavimentos musivos del yacimiento romano de Fuente Álamo (Puente Genil, Córdoba): los mosaicos de la villa”, Romula, 15, pp. 185-226.

Vargas-VÁzquez, S. y López Monteagudo, G. (2016): "La decoración musiva". En Hidalgo, R. (coord.): Las villas romanas de la Bética, 1 . Sevilla: Univ. de Sevilla, pp. 419-441.

Vargas-Vázquez, S.; López Monteagudo, G. y GarCía-Dils, S. (2017): Mosaicos romanos de Écija (Sevilla). Corpus de Mosaicos Romanos de España XIV. Madrid-Écija: Csıc-Real Academia de Ciencias, Bellas Artes y Buenas Letras 'L. Vélez de Guevara' de Écija.

VArgas-VÁzquez, S. y Romero, M. (2014): "Los mosaicos de la villa romana de Caserío Silverio". En Cisneros, M. I.; Fernández, L.-E. y Romero, M. (coords.): La villa romana de Caserio Silverio. Antequera. Antequera: Chapitel, pp. 138-167.

Vera, M. (1987): “Aportación al conocimiento de la Sevilla antigua: revisión de la excavación de Cuesta del Rosario”, Archivo Hispalense, 215, pp. 37-60. 